\title{
Elektrokoagülayon Yöntemiyle Reaktif Yellow 160 Boyar Maddesinin Giderimi
}

\author{
$1^{*}$ Ahmet AYGÜN, ${ }^{2}$ Beytullah EREN \\ ${ }^{1}$ Bursa Teknik Üniversitesi, Çevre Mühendisliği Bölümü \\ ${ }^{2}$ Sakarya Üniversitesi, Çevre Mühendisliği Bölümü
}

\section{$\ddot{O ̈ z}$}

\begin{abstract}
Demir ve alüminyum elektrotlar ile donatılmış elektrokoagülasyon prosesinin (EP) kullanıldığı çalışmada Reaktif Yellow 160 (RY160) boyarmaddesi giderimi üzerine başlangıç pH, akım yoğunluğu, iletkenlik ve elektroliz süresinin etkisi incelenmiştir. EP'de elektrot materyalinden bağımsız olarak yüksek renk giderim verimi elde edilmiştir. Optimum işletme şartları alüminyum elektrot kullanılması durumunda, $\mathrm{pH}=5$, akım yoğunluğu 100 $\mathrm{A} / \mathrm{m}^{2}$, elektroliz süresi 10 dakika, iletkenlik $1000 \mu \mathrm{S} / \mathrm{cm}$ iken demir elektrot kullanılması durumunda $\mathrm{pH}=7$, akım yoğunluğu $200 \mathrm{~A} / \mathrm{m}^{2}$, elektroliz süresi 5 dakika, iletkenlik $1000 \mu \mathrm{S} / \mathrm{cm}$ olarak belirlenmiştir. Renk giderim verimi alüminyum elektrot çifti için $2,3 \mathrm{kWsa} / \mathrm{m}^{3}$ enerji sarfiyatı ve $0,52 \$ / \mathrm{m}^{3}$ toplam maliyetle $\% 96,4$ iken demir elektrot çifti için $1,7 \mathrm{kWsa} / \mathrm{m}^{3}$ enerji sarfiyatı ve $0,28 \$ / \mathrm{m}^{3}$ toplam maliyetle $\% 95,8$ elde edilmiştir. Sonuçlar, demir elektrot kullanımının alüminyum elektrot ile karşılaştırıldığında RY160 boyarmaddesinin gideriminde daha ekonomik olduğunu göstermiştir.
\end{abstract}

Anahtar Kelimeler: Elektrokoagülasyon, Maliyet, Reaktif Yellow 160 (RY160), Renk Giderimi

\section{Decolorization of Reactive Yellow 160 Dye by Using Electrocoagulation}

\begin{abstract}
The effect of initial pH, current density, conductivity and electrolysis time on Reactive Yellow 160 (RY160) dye removal was investigated by using electrocoagulation process (EC) equipped with iron and aluminum electrodes couple. High color removal efficiency was obtained independent of electrode materials in EC. Optimum operational conditions was determined as $\mathrm{pH}=5$, current density $100 \mathrm{~A} / \mathrm{m}^{2}$, electrolysis time $10 \mathrm{~min}$ and conductivity $1000 \mu \mathrm{S} / \mathrm{cm}$ for aluminum electrodes while it was $\mathrm{pH}=7$, current density $200 \mathrm{~A} / \mathrm{m}^{2}$, electrolysis time $5 \mathrm{~min}$ and conductivity $1000 \mu \mathrm{S} / \mathrm{cm}$ for iron electrodes. Color removal was $96.4 \%$ with $2.3 \mathrm{kWh} / \mathrm{m}^{3} \mathrm{energy}$ consumption and $0.52 \$ / \mathrm{m}^{3}$ operating cost for aluminum electrode while it was $95.8 \%$ with $1.7 \mathrm{kWh} / \mathrm{m}^{3}$ energy consumption and $0,28 \$ / \mathrm{m}^{3}$ operating cost for iron electrode. The results show that, iron electrodes are more cost effective than aluminum electrodes in removal of RY160 dye.
\end{abstract}

Keywords: Color Removal, Cost, Electrocoagulation, Reactive Yellow 160 (RY160)

\section{Giriş}

Reaktif boyar maddeler, uygun koşullar altında elyaf ile kimyasal reaksiyona girerek kovalent bağ oluşturmaları, küçük ve basit molekül yapılarına sahip olmaları ve suda kolay çözünmeleri nedeniyle tekstil endüstrisinde yaygın olarak kullanılmaktadır[1]. Bununla birlikte boyamada reaktif boyar maddeler tercih edildiğinde, bu grup boyar maddelerin life bağlanma verimi az olduğundan boya banyosu atıksuyunda kullanılan boyar maddenin \% 20-40 kadarı fikse olmadan kalmaktadır [2]. Tekstil endüstrisi yoğun su tüketiminin yanında renkli ve yüzey aktif madde ile organik madde içeren yüksek kirlilik yüküne sahip atıksu oluşumu ile karakterize edilmektedir [3].
Bununla birlikte, üretim proseslerinin çeşitliliği ve işlenen elyafın özelliğine bağlı olarak oluşan atıksuyun kirletici özellikleri tesisten tesise büyük farklılıklar göstermektedir [4-5].

Tekstil atıksularının en önemli bileşenlerinden olan ve alıcı ortam üzerinde 1şık geçirgenliğini azaltarak çevresel ve estetik problemlere yol açan boyar maddelerin arıtılması sürdürülebilir bir çevre için büyük önem arz etmektedir [6]. Zira, boyar maddelerin toksik ve kanserojenik özellikleri nedeniyle ekolojik ve insan sağlığı açısından potansiyel bir tehdit unsuru olduğu da göz ard1 edilmemelidir [7]. Boyar maddelerin toksik özellik göstermeleri ve tekstil atıksularında biyolojik parçalanmaya dirençli organik madde içeriğinin 
fazla olması biyolojik yöntemlerin uygulanabilirliğini sınırlamaktadır [8]. Yine de biyolojik yöntemler kullanılarak boyar madde gidermek için yapılan arıtılabilirlik çalışmalarında, anaerobik yöntemler ile aerobik süreçlere göre daha başarılı sonuçların elde edildiği rapor edilmektedir [9]. Ayrıca ardışık anaerobik ve aerobik yöntemler kullanılmasının tekil biyolojik yöntemlere nazaran daha başarılı olduğu kaydedilmektedir [10].

Kimyasal koagülasyon/flokülasyon tekniği ile arıtımda, boyarmaddelerin kısmi bozunması ve parçalanması söz konusu olmadığı gibi toksik ve zararlı maddelerin oluşumu gözlenmediğinden tercih edilebilmektedir [11]. Bununla birlikte çamur oluşumunun diğer yöntemlerle kıyaslandığında fazla olması ve reaktif boyama tekniğinin kullanıldığı işletmelerde, boyarmaddelerin atıksuda çözünmüş formda olması nedeniyle bu yöntem arıtım alternatifi olarak tercih edilememektedir [12-13].

Kimyasal oksidasyon yöntemleri tekstil atıksularının arıtımında yaygın olarak kullanılmaktadır ve renk giderim verimleri yüksektir [14-16]. Ancak, oksitleme reaksiyonları sonucu toksik olduğu bilinen maddelerin oluşma potansiyeli fazladır [17].

Boyar maddelerin olumsuz etkilerinin en aza indirilmesi için uygulanan klasik arıtma yöntemleri alıcı ortam deşarj standartlarının sağlanması açısından yetersiz kalmaktadır. Tüm bu sorunların üstesinden gelmek için tekstil atıksularının arıtımında elektrokimyasal arıtım tekniği olan ve genellikle demir veya alüminyum elektrotların kullanıldığı elektrokoagülasyon prosesi alternatif bir yöntem olarak değerlendirilmektedir. Basit kurulum, işletme kolaylığı, güvenilir ve ekonomik çözüm üretme açısından avantajlar sunması bu yöntemin tercih edilebilirliğini arttırmaktadır [18].

$\mathrm{Bu}$ yöntemde galvanik bir hücre içerisinde elektrotlar arasında doğru akım uygulanması sonucu anodun çözünmesi ve katotta ise suyun parçalanmas1 sağlanır. Elektrokimyasal olarak oluşturulan floklar ortam pH'sınında etkisiyle monomerik ve polimerik metal hidroksit özellik gösterir, kirletici maddeler (bu çalışma özelinde boyarmaddeler) ile bağlanma, tutunma, kompleks oluşturma vb reaksiyonlar vererek birleşir, nihai olarak çöktürme veya yüzeyde toplanma şeklinde uzaklaştırılır [19].

Elektrokoagülasyon yöntemi tekstil [20-23], metal kaplama [24-26], zeytin işleme [27-28], deri [29], [30], kağıt [31], mezbaha [32] gibi birçok endüstriyel atıksuyun arıtılmasının yanında evsel atıksu [33-34] ve sızıntı sularının [35-36] arıtımında da başarı ile uygulanmıştır. Bununla birlikte, teknik olarak başarılı bir yöntemin aynı zamanda ekonomik olarak uygulanabilirliğinin belirlenmesi çevresel problemlerin sürdürülebilir olarak çözülebilmesi için önemlidir. Bu çalışmada RY160 boyar maddesinin arıtılmasında elektrokoagülasyon yönteminin temel işletme parametrelerinden olan $\mathrm{pH}$, iletkenlik, akım yoğunluğu, zaman değişkenlerinin optimum değerleri hem alüminyum hem de demir elektrot için belirlenmiş ve uygulamaya dönük olarak maliyet hesabı yapılmıştır.

\section{MATERYAL ve METOT}

\subsection{Materyal}

$\mathrm{Bu}$ çalışmada ticari olarak kullanılan reaktif boyarmaddenin (C.I. Reaktif Yellow 160), elektrokoagülasyon yöntemi kullanılarak arıtılması çalışılmıştır. Umut Kimya Tekstil San. Tic. Ltd. Şti firmasından temin edilen boyarmaddenin özellikleri Tablo 1'de özetlenirken, Şekil 1'de ise molekül yapısı verilmiştir. Deneysel çalışmalarda kullanılan tüm kimyasal maddeler analitik saflıktadır. Boyarmadde içeren çözeltilerin hazırlanmasında ultra saf su kullanılmıştır.

Tablo 1. Boyarmaddenin özellikleri

\begin{tabular}{ll}
\hline Parametre & Değer/Durum \\
\hline CAS numarası & $129898-77-7$ \\
Moleküler formülü & $\mathrm{C}_{25} \mathrm{H}_{22} \mathrm{CIN}_{9} \mathrm{Na}_{2} \mathrm{O}_{12} \mathrm{~S}_{3}$ \\
Molekül ağırlığı $(\mathrm{g} / \mathrm{mol})$ & 818.13 \\
Fiziksel Hali & Yeşil-açık sarı görünümde \\
\hline
\end{tabular}




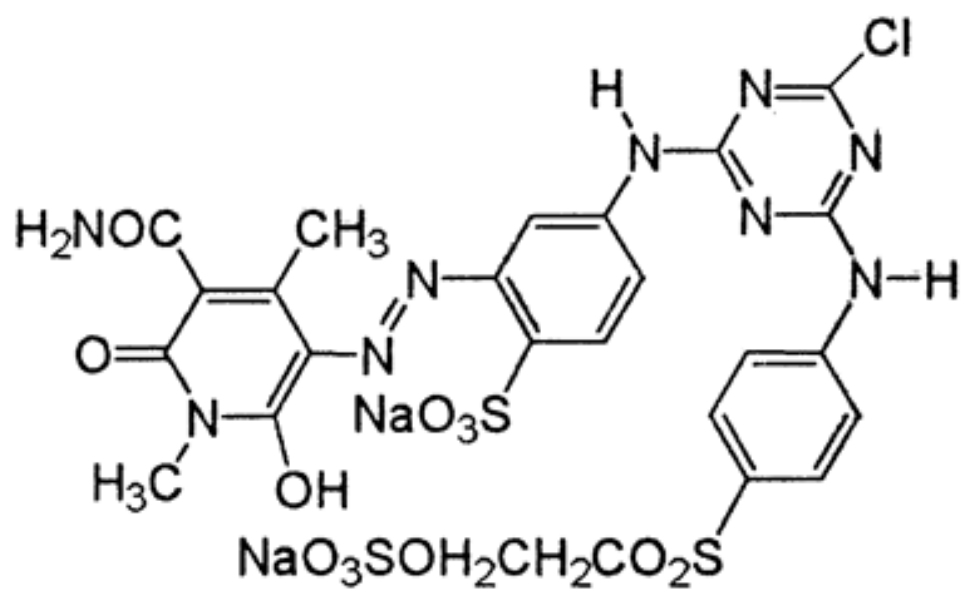

Şekil 1. Moleküler yapı (C.I. Reaktif Yellow 160)

\subsection{Deney Düzeneği}

Deneysel çalışmalar Şekil 2'de şematik olarak gösterilen deneysel düzenek kullanılarak sürdürülmüştür. $50 \times \quad$ x $50 \quad$ x $5 \mathrm{~mm}$ ebatlarında alüminyum ve demir elektrot çiftlerinin kullanıldığ1 çalışmada elektrotlar arası mesafe $25 \mathrm{~mm}$ 'dir. 1 litrelik hacme sahip pleksiglas malzemeden yapılmış elektrokoagülasyon reaktöründe, akım ve voltaj kontrolü EA-PS 3032-10 B marka (0-32 V gerilim ve 0-10 A akım ayarlı) dijital doğru akım güç kaynağı ile sağlanmıştır. Elektroliz süresi boyunca karışım için manyetik karıştırıcı kullanılmıştır.

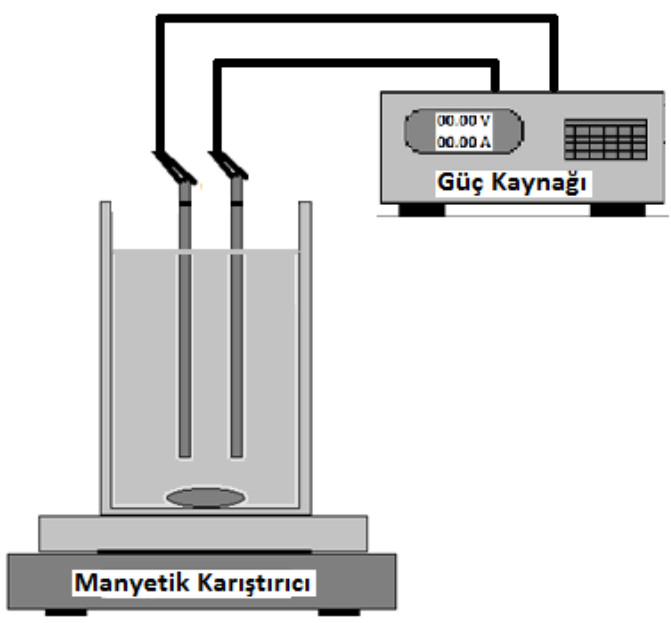

Şekil 2. Deney Düzeneği

\subsection{Deneysel İşlem}

Elektrotların yerleştirilmesinden sonra elektrokoagülasyon reaktörüne $500 \mathrm{~mL} 100 \mathrm{mg} / \mathrm{L}$ boyarmadde içeren çözelti konulmuştur. Çözeltinin pH değeri $0.1 \mathrm{M}$ HCI ve $0.1 \mathrm{M} \mathrm{NaOH}$ kullanılarak, iletkenlik değeri ise katı $\mathrm{NaCI}$ ile tanımlanmış deney şartlarına ayarlanmıştır. İstenen akım ve voltaj değerleri dijital güç kaynağında ayarlanıp sistem çalıştırılmıştır.

Elektrokoagülasyon deneylerinin hemen ardından ölçümler üzerine flokların girişim yapmasının engellenmesi için reaktörden alınan numuneler 0.45 $\mu \mathrm{m}$ gözenek çaplı filttre kâğıdı kullanılarak süzülmüş ve süzülen numunelerde renk tayini yapılmıştır. Her deneyden önce elektrotların yüzeyleri aseton ile y1kand1ktan sonra deney süresince elektrot yüzeyinde biriken kir ve pasların giderimi, önceden hazırlanan \% 37'lik $100 \mathrm{~mL}$ HCI ve \% 2.8'lik 200 $\mathrm{ml}$ hekzametilen tetramin $\left(\left(\mathrm{CH}_{2}\right)_{6} \mathrm{~N}_{4}\right)$ karışımı ile oluşturulan temizleme çözeltisinde elektrotların 5 dakika bekletilmesi ile sağlanmıştır [37]. Her bir deney setinde elektrot aşınım miktarının (kütle kaybının) belirlenmesi için elektrotlar tartılmış ve not edilmiştir [38].

\subsection{Analitik Metot}

RY160 boyarmaddesi için maksimum absorbans elde edilen dalga boyunun DR $5000 \mathrm{UV}-\mathrm{Vis}$ spektrofotometre ile $190 \mathrm{~nm}$ ile $800 \mathrm{~nm}$ arasinda 1 $\mathrm{nm}$ aralıklarla yapılan tarama sonucu $426 \mathrm{~nm}$ olduğu tespit edilmiştir. $0-100 \quad \mathrm{mg} / \mathrm{L} \quad \mathrm{RY} 160$ içeren çözeltiler kullanılarak kalibrasyon eğrisi oluşturulmuş ve boyarmadde konsantrasyonu ile absorbans arasındaki ilişki matematiksel olarak belirlenmiştir. Elde edilen denklem yardımıyla arıtılabilirlik çalışmaları sonucu absorbans değeri belirlenen numunelerin boyarmadde konsantrasyonu tespit edilmiştir. Deneysel çalışmalarda renk giderim verimi Eşitlik 1'de verilen denklem yardımıyla belirlenmiştir.

$$
\text { (\%) } C_{\text {Renk }}=\left(\frac{\mathrm{C}_{0}-\mathbf{C}_{e}}{\mathbf{C}_{0}}\right) * 100
$$

Burada $\mathrm{C}_{0}$, seçilen dalga boyundaki başlangıç boya konsantrasyonu (mg/L), $\mathrm{C}_{\mathrm{e}}$, seçilen dalga boyundaki arıtım sonrası boya konsantrasyonunu $(\mathrm{mg} / \mathrm{L})$ ifade etmektedir. 


\subsection{Maliyet Analizi}

Elektrokoagülasyon yöntemiyle boyarmadde gidermede işletme maliyeti hesaplanırken elektrik sarfiyatı ile elektrot tüketimleri ve oluşan çamurun bertaraf edilmesi dikkate alınmıştır. Hesaplamalarda tüketilen elektrot materyali için birim fiyat alüminyum elektrot için $1.78 \$ / \mathrm{kg}$, demir elektrot için $0.93 \$ / \mathrm{kg}$ olarak kabul edilirken, elektrik sarfiyatı için maliyet $0.13 \$ / \mathrm{kWh}$ ve oluşan çamurun bertaraf edilmesi için maliyet $0.10 \$ / \mathrm{kg}$ olarak kabul edilmiştir [39].

\section{TARTIŞMA ve SONUÇ}

Bu çalışmada elektrokoagülasyon prosesi ile reaktif boyarmadde giderim verimi üzerine başlangıç $\mathrm{pH}$, iletkenlik, akım yoğunluğu, elektroliz süresi (zaman) gibi prosese özgü işletme parametrelerin etkisi araştırılmıştır. Elektrokoagülasyon prosesinde hem demir hem de alüminyum elektrot kullanılması durumunda katotta oluşan hidrojen gazı çıkışı nedeniyle floklar reaktörün üst kısmında toplanmış ve net bir katı sıvı ayırımı gözlenmiştir.

\subsection{Başlangıç pH'ın Etkisi}

pH galvanik hücre içerisinde meydana gelen reaksiyonları ve oluşan flok türlerini direkt olarak etkilediği için büyük öneme sahiptir. Elektrokoagülasyon yönteminin kullanıldı̆̆ çalışmalarda arıtma performansının başlangıç $\mathrm{pH}$ ' sına bağlı olduğu kadar arıtım işlemi sonunda ulaşılan $\mathrm{pH}$ değerlerine de bağlı olduğu rapor edilmiştir. Şekil 3 'te başlangıç pH değerinin renk giderimi üzerine etkisi alüminyum ve demir elektrot çiftlerinin kullanılması durumu için verilmiştir. pH etkisinin belirlenmesi için yapılan deneysel çalışmalarda işletme şartları olarak 0.5 A akım (akım yoğunluğu olarak $100 \mathrm{~A} / \mathrm{m}^{2}$ ), NaCI eklenerek 1000 $\mu \mathrm{S} / \mathrm{cm}$ iletkenlik değeri ve $200 \mathrm{rpm}$ karıştırma hızı sabit tutulmuştur. Ön deneysel çalışmalar neticesinde, elektroliz süresi alüminyum elektrot çifti için 10 dakika, demir elektrot çifti için ise 5 dakika olarak belirlenmiştir.

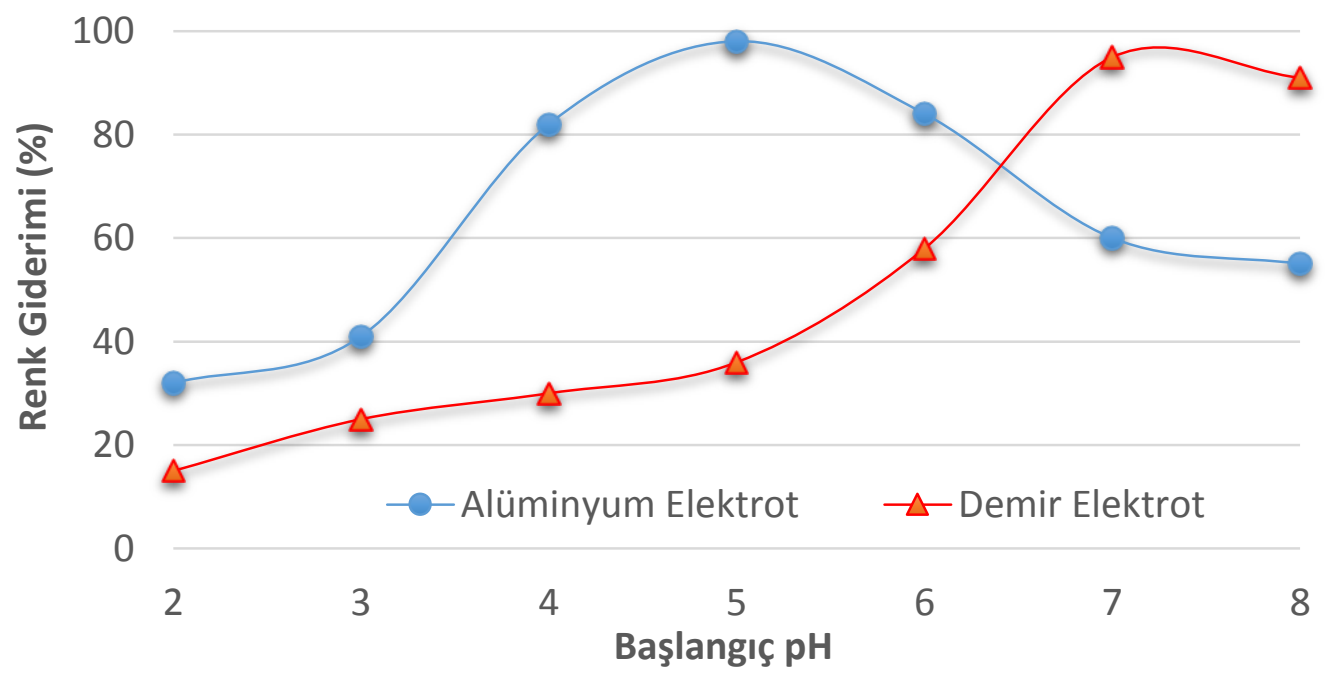

Şekil 3. Başlangıç pH değerinin renk giderimi üzerine etkisi

Alüminyum ve demir elektrotlarının çözünmesi ile çözünen elektrot materyaline özgü flok oluşumu gözlenmektedir. Şekil 3'ten de görüleceği üzere en iyi renk giderme verimi alüminyum elektrotun başlangıç pH değeri 5, demir elektrotun ise başlangıç pH değeri 7 olduğunda elde edilmiştir. Alüminyum elektrotlar kullanılarak yürütülen deneysel çalışmalarda pH'ya bağlı olarak monomerik ve polimerik alüminyum hidroksit kompleks türlerini oluşmaktadır. Bu kompleksler $\mathrm{pH}$ 4-7 aralığında polimerize olma eğilimindedirler. En çok bilinen monomerik türler; $\mathrm{Al}(\mathrm{OH})^{+2}, \mathrm{Al}(\mathrm{OH})_{2}^{+}$, $\mathrm{Al}_{2}(\mathrm{OH})_{2}^{+4}, \quad \mathrm{Al}(\mathrm{OH})_{4}^{-}$ve en çok bilinen polimerik türler ise; $A l_{6}(\mathrm{OH})_{15}^{+3}, A l_{7}(\mathrm{OH})_{17}^{+4}$,
$A l_{8}(O H)_{20}^{+4}, A l_{13} O_{4}(O H)_{24}^{+7}, A l_{13}(O H)_{34}^{+5}$ 'dir. Değişik türlerin oluşma oranları renk giderme aşamasında belirleyici öneme sahip olmaktadır. Düşük $\mathrm{pH}$ değerlerinde flokülasyon ile çökelme, $\mathrm{pH}$ $>\quad 6.5$ olduğu durumlarda ise adsorpsiyon mekanizması ile renk giderimi gerçekleştiği rapor edilmektedir. Demir elektrot kullanılarak yürütülen deneysel çalışmalarda, elektrotun $\mathrm{Fe}^{+2}$ ve $\mathrm{Fe}^{+3}$ olarak anodik çözünmesi ile $\mathrm{Fe}(\mathrm{OH})_{\mathrm{n}}$ kompleksleri oluşmaktadır. Demir kompleksleri ile çöktürme reaksiyonu baskın mekanizma olarak karşımıza çıkmaktadır.

Elektrokoagülasyon prosesinde $\mathrm{pH}$ değeri, elektroliz süresi boyunca katotta suyun parçalanması 
nedeniyle oluşan hidrojen gazı çıkışı ve hidroksit iyonlarının birikimi nedeniyle artmaktadır. Hem alüminyum hem de demir elektrot kullanılan çalışmalarda gözlenen başlangıç ve arıtım sonrası $\mathrm{pH}$ değerleri Şekil 4'te verilmiştir.

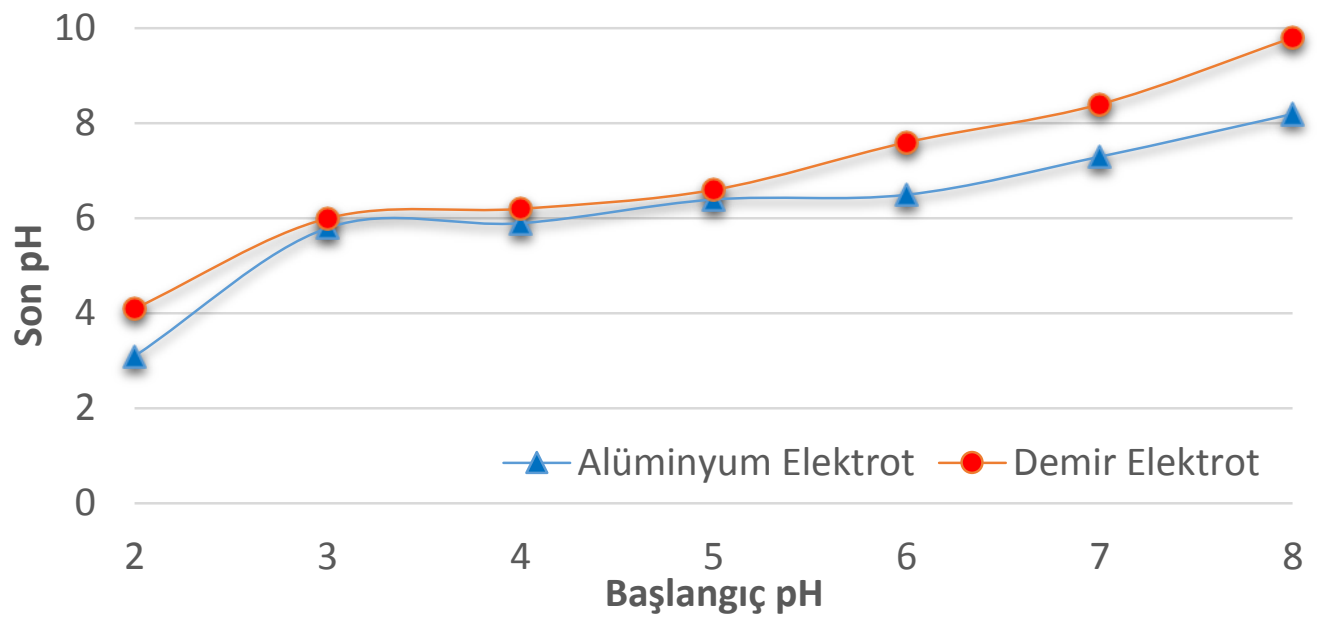

Şekil 4. Başlangıç pH değerinin son $\mathrm{pH}$ değeri üzerine etkisi

\subsection{Akım Yoğunluğunun Etkisi}

Akım yoğunluğu, birim elektrot alanından geçen akım olarak ifade edilir. Akım yoğunluğunun miktarı, anotta çözünen metal iyonlarının üretim hızını ve katotta oluşacak kabarcık hızı ile büyüklüğünü etkilediğinden oluşan flokların miktarını, yapısını ve oluşumunu da etkiler. Akım yoğunluğu, aşırı oksijenin ve olası sıcaklık artışının önlenebilmesi için kontrol edilmelidir [40]. Elektrokoagülasyon prosesi, verimli olarak işletilebilmesi için kritik akım yoğunluğunda çalıştırılmalıdır. Akım yoğunluğunun artışı ile verimde artış olur, bu kritik değerden sonra akım yoğunluğunun arttırılması ile çıkış suyu kalitesinde önemli bir iyileşme gözlenmemektedir. Çözünen elektrot miktarı Faraday kanunları çerçevesinde elektrotun cinsine göre değişmektedir [41].

Akım yoğunluğunun renk giderme verimine etkisini incelemek amacı alüminyum elektrot çifti için başlangıç pH değeri 5 ve elekroliz süresi 10 dakika, demir elektrot çifti için başlangiç $\mathrm{pH}$ değeri 7 ve elektroliz süresi 5 dakika olarak ayarlanmıștır. Katı $\mathrm{NaCI}$ eklenerek $1000 \mu \mathrm{S} / \mathrm{cm}$ iletkenlik değeri ve 200 rpm karıştırma hızı sabit tutulmuştur. 20-120 A/m² aralığında akım yoğunlukları uygulanması ile alüminyum ve demir elektrot çiftleri için elde edilen renk giderim verimi değişimleri Şekil 5'te özetlenmiştir.

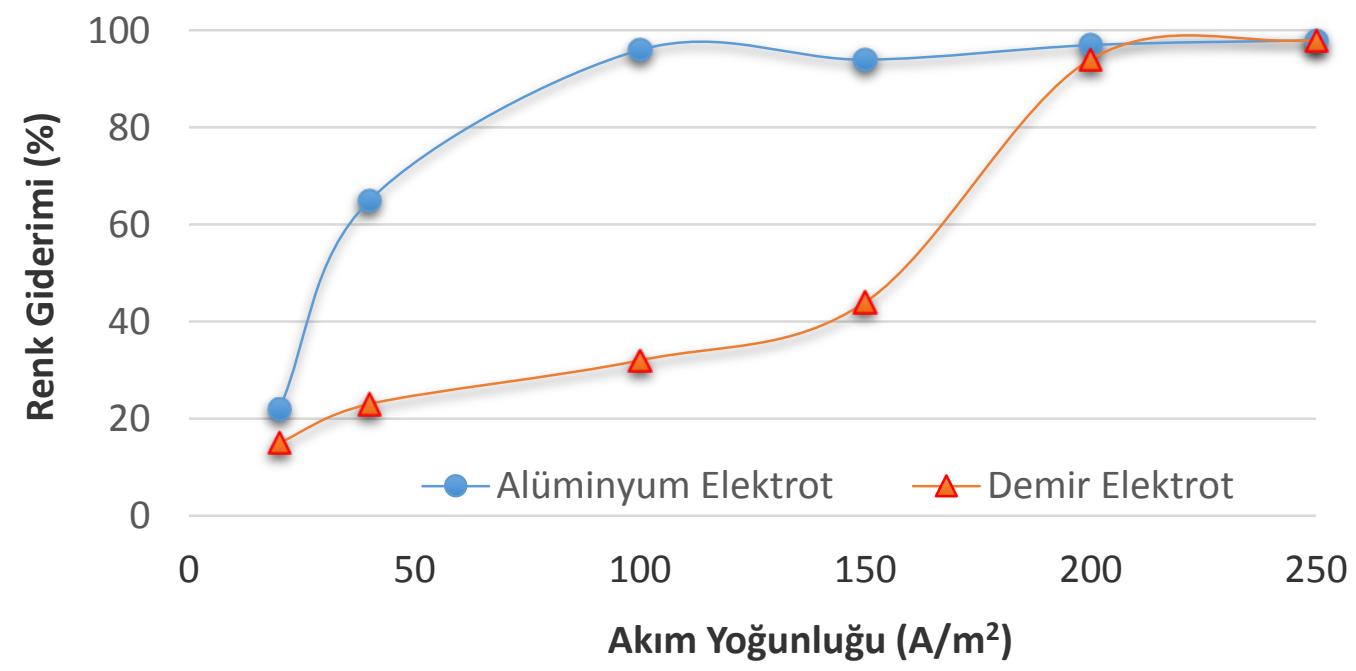

Şekil 5. Akım yoğunluğunun renk giderim verimi üzerine etkisi

Şekil 5 'te alüminyum elektrot çifti için $20 \mathrm{~A} / \mathrm{m}^{2}$ ile $100 \mathrm{~A} / \mathrm{m}^{2}$ arasında renk giderim veriminin hızlı bir şekilde arttığ $1,100 \mathrm{~A} / \mathrm{m}^{2}$ ve $250 \mathrm{~A} / \mathrm{m}^{2}$ aralığında ise renk giderme veriminde değişimin sınırlı olduğu görülmektedir. Bununla birlikte, demir elektrot çifti kullanıldığında ise akım yoğunluğunun $200 \mathrm{~A} / \mathrm{m}^{2}$ ye 
kadar arttırılması gerekmektedir. Akım yoğunluğu elektrik sarfiyatı ve elektrot çözünmesi üzerinde en önemli etkiye sahip olan değişken durumundadır. Alüminyum elektrot için akım yoğunluğu 20 $\mathrm{A} / \mathrm{m} 2$ 'den $250 \mathrm{~A} / \mathrm{m} 2$ 'ye çıkarıldı ğından potansiyel fark 1,6 volttan 10.4 volta yükselmiştir. Demir elektrot için de durum farklı değildir. Nihai olarak optimum akım yoğunluğu değerleri alüminyum elektrot kullanılmas1 durumunda $100 \mathrm{~A} / \mathrm{m}^{2}$, demir elektrot kullanıldığında ise $200 \mathrm{~A} / \mathrm{m}^{2}$ olarak belirlenmiştir.

\subsection{Elektrokoagülasyon Üzerine İletkenliğin Etkisi}

Çözelti iletkenliğinin renk giderme verimine etkisini incelemek amacıyla boyarmadde içeren çözeltisinin iletkenliği, katı NaCI ilavesi ile $1000-5000 \mu \mathrm{S} / \mathrm{cm}$ aralığında çalışılmıştır. Deneysel çalışmalar alüminyum ve demir için belirlenen optimum başlangıç pH'sı, akım yoğunluğu ile $200 \mathrm{rpm}$ karıştırma hızında alüminyum elektrot çiftleri için 10 dakikalık elektroliz süresi, demir elektrot çiftleri için 5 dakikalık elektroliz süresinde gerçekleştirilmiştir. Şekil 6'da iletkenlik değişiminin renk giderimi üzerine etkisi gösterilmiştir.

Şekil 6'dan da görüleceği üzere elektriksel iletkenlik artışıyla elektrotlar arasındaki potansiyel farkın azalması sonucu anodik oksidasyonda düşüş buna bağlı olarak da renk giderme veriminde sınırlı da elektrot türünden bağımsız olarak azalma meydana gelmiştir. Elektriksel iletkenlik artışı ortamda klorür iyonlarının artışı anlamına gelmektedir. Organik moleküllü kirleticilerin olduğu bir elektrokimyasal hücrede oksidasyon nedeniyle organoklorlu toksik maddelerin oluşması kaçınılmaz olacaktır. Bu nedenle iletkenlik artışı potansiyel farkın azalması ile ihtiyaç duyulan elektrik maliyetinin azalması ile sonuçlansa da hem verimde meydana gelen azalma hem de toksik madde oluşma potansiyelinin artış1 nedeniyle her iki elektrot türü için de $1000 \mu \mathrm{S} / \mathrm{cm}$ elektriksel iletkenlik optimum olarak kabul edilmiştir.

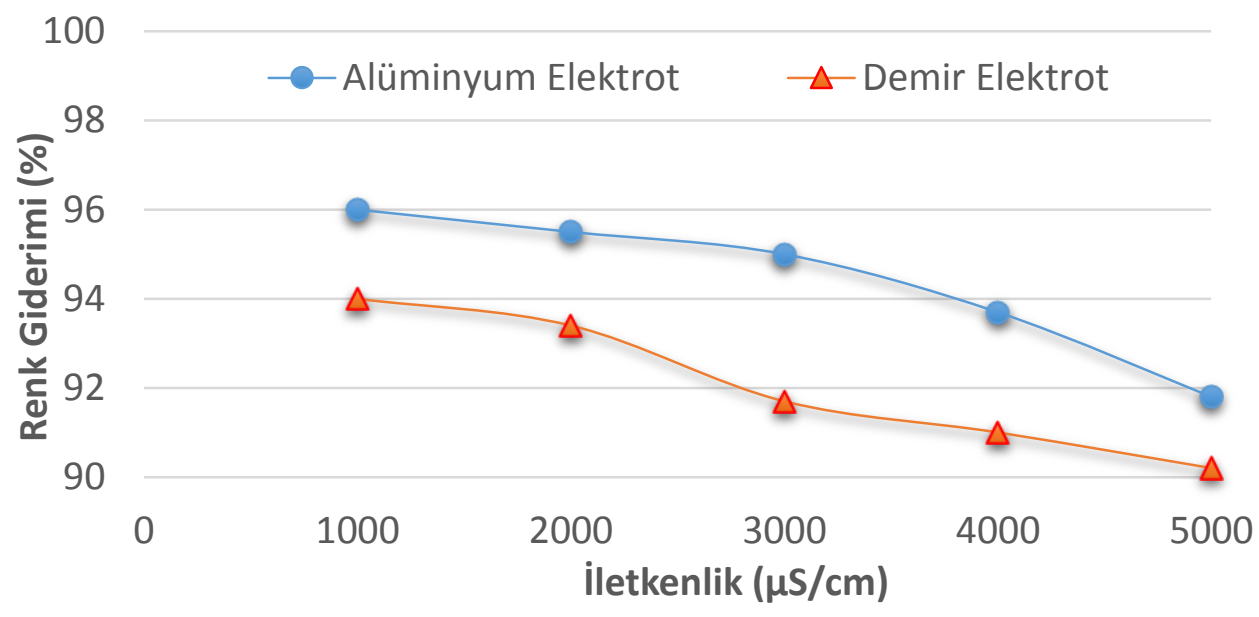

Şekil 6. Elektriksel iletkenliği renk giderim verimi üzerine etkisi

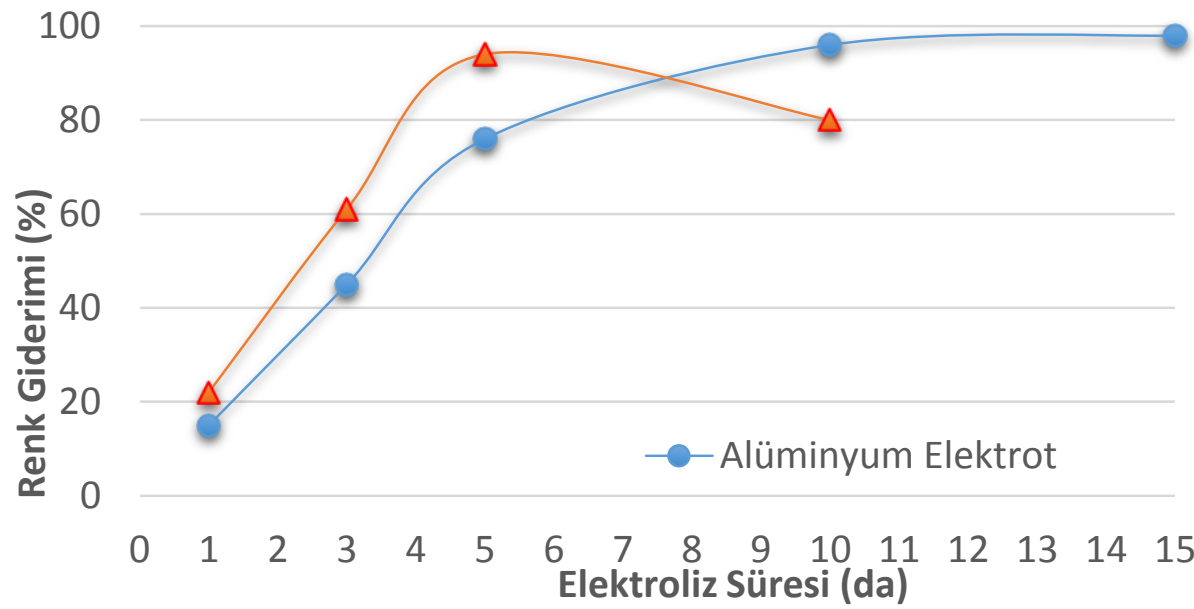

Şekil 7. Zamanın renk giderim verimi üzerine etkisi 


\subsection{Zamanın Etkisi}

Çözünen elektrot miktarı elektroliz süresinin artıșına bağlı olarak artmaktadır. Kimyasal madde miktarının kontrollü olarak elektrokimyasal çözünme ile arttırıldığı proseste belirlenen optimum arıtım süre aş1ldıktan sonra elektroliz sürenin arttırılması ile kirletici giderim veriminde iyileşme meydana gelmemekte ve genellikle sabit kalmaktadır. Zamanın renk giderme verimine etkisini incelemek amaciyla 0-15 dakikalar arasında belirlenen aralıklarla reaktörden numuneler alınmıştır. Zamanın renk giderim verimi üzerine etkisi Şekil 7'de verilmiştir.

Şekil 7'de alüminyum elektrot çifti için optimum süresinin 10 dakika olduğu, süre artışı ile renk giderim veriminde artış meydana gelmediği görülmektedir. Buna karşın demir elektrot kullanılan çalışmada ilk dakikalarda demir elektrotun çözünmesi ile renk değişimi olmazken 4. dakikadan sonra çözelti renginde demir +2 oluşumu nedeniyle yeşerme meydana gelmiş ve 5 . dakikadan sonra renk giderim veriminde azalma gözlenmiştir. 10. dakikadan sonra demir kaynaklı aşırı renk oluşumu nedeniyle ölçüm alınmamıştır. Optimum elektroliz süresi 5 dakika olarak kabul edilmiştir.

\subsection{Aritım maliyeti}

Demir elektrot kullanılması durumunda $0.28 \$ / \mathrm{m}^{3}$, alüminyum elektrot kullanılması durumunda ise $0.52 \$ / \mathrm{m}^{3}$ işletme maliyeti olarak hesaplanmıştır. Enerji maliyetleri demir ve alüminyum elektrot çiftleri için sırasıyla $1.7 \mathrm{kWsa} / \mathrm{m}^{3}$ ve $2.3 \mathrm{kWsa} / \mathrm{m}^{3}$ olarak hesaplanmıştır. Demir elektrotun alüminyum elektroda nazaran daha ucuz olması, daha kısa elektroliz süresinde renk giderimi işleminin sağlanması, akım verimliliği daha az olduğundan çözünme sonucu oluşan çamurun miktarının daha az olması nedeniyle ekonomik olduğu tespit edilmiştir.

\section{DEĞERLENDİRME}

Alüminyum ve demir elektrot çiftleri kullanılarak yürütülen arıtılabilirlik çalışmaları sonucunda elektrokoagülasyon prosesinin Reaktif Yellow 160 boyarmaddesinin arıtılmasında etkili bir yöntem olduğu tespit edilmiştir. Tekstil endüstrisinin yüksek su kullanımı ve açığa çıkan atıksu miktarı göz önüne alındığında, çok yüksek giderme verimlerine ulaşan bu yöntemin çevrenin ve doğal kaynakların korunmasında önemli bir alternatif atıksu arıtma prosesi olarak değerlendirilmesi gerekmektedir. Renk giderim verimi alüminyum elektrot çifti için $2,3 \mathrm{kWsa} / \mathrm{m}^{3}$ enerji sarfiyat 1 ve $0,52 \$ / \mathrm{m}^{3}$ toplam maliyetle \%96,4 iken demir elektrot çifti için 1,7 $\mathrm{kWsa} / \mathrm{m}^{3}$ enerji sarfiyatı ve $0,28 \$ / \mathrm{m}^{3}$ toplam maliyetle \%95,8 elde edilmiştir. Bu sonuçlara göre, elektrokoagülasyon prosesinde demir elektrot çifti kullanımı ile daha ekonomik arıtım yapılabileceği tespit edilmiştir.

\section{KAYNAKLAR}

[1] M. A. Al-Ghouti, M. A. M. Khraisheh, S. J. Allen, and M. N. Ahmad, "The removal of dyes from textile wastewater: A study of the physical characteristics and adsorption mechanisms of diatomaceous earth," Journal of Environmental Management, vol. 69, no. 3, pp. 229-238, 2003.

[2] Y. Gunes, R. Atav, and O. Namirti, "Effectiveness of ozone in decolorization of reactive dye effluents depending on the dye chromophore," Textile Research Journal, vol. 82, no. 10, pp. 9941000, 2011.

[3] J. Blanco, F. Torrades, M. Morón, M. Brouta-Agnésa, and J. García-Montaño, "PhotoFenton and sequencing batch reactor coupled to photo-Fenton processes for textile wastewater reclamation: Feasibility of reuse in dyeing processes," Chemical Engineering Journal, vol. 240, pp. 469-475, 2014.

[4] Y. K. Ong, F. Y. Li, S. P. Sun, B. W. Zhao, C. Z. Liang, and T. S. Chung, "Nanofiltration hollow fiber membranes for textile wastewater treatment: Lab-scale and pilot-scale studies," Chemical Engineering Science, vol. 114, pp. 51-57, 2014.

[5] F. Ciner, S. K. A. Solmaz, T. Yonar, and G. E. Ustun, "Treatability studies on wastewater from textile dyeing factories in Bursa, Turkey," International Journal of Environment and Pollution, vol. 19, no. 4, pp. 403-407, 2003.

[6] Y. Uysal, D. Aktas, and Y. Caglar, "Determination of Colour removal efficiency of Lemna minor L. from industrial effluents," Journal of Environmental Protection and Ecology, vol. 15, no. 4, pp. 1718-1726, 2014.

[7] Z. Aksu and G. Dönmez, "Combined effects of molasses sucrose and reactive dye on the growth and dye bioaccumulation properties of Candida tropicalis," Process Biochemistry, vol. 40, no. 7, pp. 2443-2454, 2005.

[8] H. S. Rai, M. S. Bhattacharyya, J. Singh, T. K. Bansal, P. Vats, and U. C. Banerjee, "Removal of Dyes from the Effluent of Textile and Dyestuff Manufacturing Industry: A Review of Emerging Techniques With Reference to Biological Treatment," Critical Reviews in Environmental Science and Technology, vol. 35, no. 3, pp. 219-238, 2005.

[9] H. Kocyigit and A. Ugurlu, "Biological decolourization of reactive azo dye by anaerobic/aerobic sequencing batch reactor system," Global NEST journal, vol. 17, no. X, pp. 1-10, 2015. [10] S. Ozdemir, K. Cirik, D. Akman, E. Sahinkaya, and O. Cinar, "Treatment of azo dyecontaining synthetic textile dye effluent using 
sulfidogenic anaerobic baffled reactor," Bioresource Technology, vol. 146, pp. 135-143, 2013.

[11] C. S. D. Rodrigues, L. M. Madeira, and R. A. R. Boaventura, "Treatment of textile dye wastewaters using ferrous sulphate in a chemical coagulation/flocculation process," Environmental Technology, vol. 34, no. 6, pp. 719-729, 2013.

[12] V. Golob, A. Vinder, and M. Simonič, "Efficiency of the coagulation/flocculation method for the treatment of dyebath effluents," Dyes and Pigments, vol. 67, no. 2, pp. 93-97, 2005.

[13] O. T. Can, M. Kobya, E. Demirbas, and M. Bayramoglu, "Treatment of the textile wastewater by combined electrocoagulation," Chemosphere, vol. 62, no. 2, 2006.

[14] S. Karthikeyan, A. Titus, A. Gnanamani, A. B. Mandal, and G. Sekaran, "Treatment of textile wastewater by homogeneous and heterogeneous Fenton oxidation processes," Desalination, vol. 281, no. 1, pp. 438-445, 2011.

[15] S. Şahinkaya, "COD and color removal from synthetic textile wastewater by ultrasound assisted electro-Fenton oxidation process," Journal of Industrial and Engineering Chemistry, vol. 19, no. 2, pp. 601-605, 2013.

[16] M. F. Sevimli and C. Kinaci, "Decolorization of textile wastewater by ozonation and Fenton's process," in Water Science and Technology, 2002, vol. 45, no. 12, pp. 279-286.

[17] N. Daneshvar, A. Oladegaragoze, and N. Djafarzadeh, "Decolorization of basic dye solutions by electrocoagulation: An investigation of the effect of operational parameters," Journal of Hazardous Materials, vol. 129, no. 1-3, pp. 116-122, 2006.

[18] M. Y. Mollah, R. Schennach, J. R. Parga, and D. L. Cocke, "Electrocoagulation (EC)--Science and Applications.," Journal of Hazardous Materials, vol. 84, no. 1, pp. 29-41, 2001.

[19] M. Y. A. Mollah, P. Morkovsky, J. A. G. Gomes, M. Kesmez, J. Parga, and D. L. Cocke, "Fundamentals, present and future perspectives of electrocoagulation," Journal of Hazardous Materials, vol. 114, no. 1-3. pp. 199-210, 2004.

[20] I. Arslan-alaton, M. Kobya, A. Akyol, and M. Bayramoğlu, "Electrocoagulation of azo dye production wastewater with iron electrodes: Process evaluation by multi-response central composite design," Coloration Technology, vol. 125, no. 4, pp. 234-241, 2009.

[21] M. Kobya, E. Demirbas, O. T. Can, and M. Bayramoglu, "Treatment of levafix orange textile dye solution by electrocoagulation," Journal of Hazardous Materials, vol. 132, no. 2-3, 2006.

[22] O. T. Can, M. Kobya, E. Demirbas, and M. Bayramoglu, "Treatment of the textile wastewater by combined electrocoagulation," Chemosphere, vol. 62, no. 2, pp. 181-187, 2006.

[23] C. S. Keskin, A. Özdemir, and I. A. Şengil, "Simultaneous decolorization of binary mixture of reactive yellow and acid violet from wastewaters by electrocoagulation," Water Science and Technology, vol. 63, no. 8, pp. 1644-1650, 2011.

[24] H. A. Kabuk, Y. Avsar, F. Ilhan, and K. Ulucan, "Comparison of $\mathrm{pH}$ Adjustment and Electrocoagulation Processes on Treatability of Metal Plating Wastewater," Separation Science and Technology, vol. 49, no. 4, pp. 613-618, 2014.

[25] K. K. Dermentzis, A. Christoforidis, and E. Valsamidou, "Removal of nickel, copper, zinc and chromium from synthetic and industrial wastewater by electrocoagulation," International Journal of Environmental Sciences, vol. 1, no. 5, pp. 697-710, 2011.

[26] F. Akbal and S. Camci, "Comparison of electrocoagulation and chemical coagulation for heavy metal removal," Chemical Engineering and Technology, vol. 33, no. 10, pp. 1655-1664, 2010.

[27] Ü. Tezcan Ün, S. Uğur, A. S. Koparal, and Ü. Bakir Öğütveren, "Electrocoagulation of olive mill wastewaters," Separation and Purification Technology, vol. 52, no. 1, pp. 136-141, 2006.

[28] H. Inan, A. Dimoglo, H. Şimşek, and M. Karpuzcu, "Olive oil mill wastewater treatment by means of electro-coagulation," Separation and Purification Technology, vol. 36, no. 1, pp. 23-31, 2004.

[29] O. Apaydin, U. Kurt, and M. T. Gonullu, "An Investigation on the Treatment of Tannery Wastewater by Electrocoagulation," Water, vol. 11, no. 4, pp. 546-555, 2009.

[30] A. Deghles and U. Kurt, "Treatment of tannery wastewater by a hybrid electrocoagulation/electrodialysis process," Chemical Engineering and Processing: Process Intensification, vol. 104, pp. 43-50, 2016.

[31] M. Uğurlu, A. Gürses, Ç. Doğar, and M. Yalçin, "The removal of lignin and phenol from paper mill effluents by electrocoagulation," Journal of Environmental Management, vol. 87, no. 3, pp. 420-428, 2008.

[32] M. Kobya, E. Senturk, and M. Bayramoglu, "Treatment of poultry slaughterhouse wastewaters by electrocoagulation," Journal of Hazardous Materials, vol. 133, no. 1-3, pp. 172-176, 2006.

[33] C. Sarala, "Domestic Wastewater Treatment by Electrocoagulation with $\mathrm{Fe}-\mathrm{Fe}$ Electrodes," International Journal of Engineering Trends and Technology, vol. 3, no. 4, pp. 530-533, 2012.

[34] S. Barişçi and O. Turkay, "Domestic greywater treatment by electrocoagulation using hybrid electrode combinations," Journal of Water Process Engineering, vol. 10, pp. 56-66, 2016.

[35] F. Ilhan, U. Kurt, O. Apaydin, and M. T. Gonullu, "Treatment of leachate by electrocoagulation using aluminum and iron electrodes," Journal of Hazardous Materials, vol. 154, no. 1-3, pp. 381-389, 2008. 
[36] S. Top, E. Sekman, S. Hoşver, and M. S. Bilgili, "Characterization and electrocaogulative treatment of nanofiltration concentrate of a full-scale landfill leachate treatment plant," Desalination, vol. 268, no. 1-3, pp. 158-162, 2011.

[37] O. T. Can and M. Bayramoglu, "The effect of process conditions on the treatment of benzoquinone solution by electrocoagulation," Journal of Hazardous Materials, vol. 173, no. 1-3, pp. 731-736, 2010.

[38] M. Bayramoglu, M. Kobya, O. T. Can, and M. Sozbir, "Operating cost analysis of electrocoagulation of textile dye wastewater," Separation and Purification Technology, vol. 37, no. 2, pp. 117-125, 2004.
[39] E. Demirbas and M. Kobya, "Operating cost and treatment of metalworking fluid wastewater by chemical coagulation and electrocoagulation processes," Process Safety and Environmental Protection, vol. 105, pp. 79-90, 2017.

[40] I. A. Şengil, S. Kulaç, and M. Özacar, "Treatment of tannery liming drum wastewater by electrocoagulation," Journal of Hazardous Materials, vol. 167, no. 1-3, pp. 940-946, 2009.

[41] P. K. Holt, G. W. Barton, M. Wark, and C. A. Mitchell, "A quantitative comparison between chemical dosing and electrocoagulation," Colloids and Surfaces A: Physicochemical and Engineering Aspects, vol. 211, no. 2-3, pp. 233-248, 2002. 